\title{
ANÁLISE DA SUBJETIVIDADE DAS DECISÕES JUDICIAIS SOB A PERSPECTIVA RELATIVISTA DE HANS KELSEN
}

\author{
Luiz Carlos De Oliveira Paiva Júnior ${ }^{1}$ \\ Leonardo Medeiros Junior ${ }^{2}$
}

RESUMO: A concepção do relativismo filosófico de Hans Kelsen, como fundamento da Teoria Pura do Direito, traz consequências na interpretação judicial das normas e interfere na aplicação do Direito. Propõe-se uma análise hermenêutica da subjetividade das decisões judiciais. Trata sobre a filosofia relativista e da exclusão da moralidade no conceito de Direito. Analisa a criação normativa pelo judiciário, a discricionariedade do magistrado e a interpretação sem recorrer à moral. Utilizou-se a pesquisa teórico-bibliográfica e o procedimento metodológico indutivo. Conclui-se que, embora o magistrado se arrogue detentor de valores morais absolutos, suas decisões devem ser vistas como um ato de vontade.

Palavras-chave: Hans KelsenDecisão JudicialRelativismoHermenêuticaTeoria Pura do Direito

\section{ANALYSIS OF THE SUBJECTIVITY OF JUDICIAL DECISIONS UNDER THE RELATIVE PERSPECTIVE OF HANS KELSEN}

ABSTRACT: Hans Kelsen's conception of philosophical relativism, as the basis of the Pure Theory of Law, has consequences in the judicial interpretation of norms and interferes with the application of Law. It is proposed a hermeneutical analysis of the subjectivity of judicial decisions. It is about the relativist philosophy and the exclusion of morality in the concept of Law. The normative creation by the judiciary, the discretion of the magistrate and the interpretation without recourse to morality will be analyzed. The theoretical-bibliographic research and the inductive methodological procedure were used. It is concluded that, although the magistrate arrogates holder of absolute moral values his decisions should be seen as an act of will.

Keywords: Hans KelsenJudicial decisionRelativismHermeneuticsPure Theory of Law

\footnotetext{
${ }^{1}$ Mestrando em Direito Constitucional pela UFRN. Doutorando em Direito pela UBA. Pós-graduado em Direitos Humanos pela UFCG. Assessor Judiciário da Presidência do TJRN. Docente do Curso de Direito da FACEP.

${ }^{2}$ Servidor Público Estadual e Professor. Mestrando em Direito Constitucional pela Universidade Federal do Rio Grande do Norte (UFRN). Professor do Centro Universitário do Rio Grande do Norte (UNI-RN). leonardomjunior@hotmail.com.
} 


\section{INTRODUÇÃO}

O presente estudo científico propõe uma abordagem hermenêutica da subjetividade das decisões judiciais sob a perspectiva de Hans Kelsen considerando o relativismo moral e o problema da criação normativa pelo judiciário, representado pelo magistrado julgador.

A interpretação autêntica das normas acarreta a discricionariedade das decisões judiciais tendo em vista o reconhecimento da falibilidade da determinação semântica das normas gerais aos casos concretos e, como consequência do relativismo filosófico, a impossibilidade da aplicação de princípios morais como forma de resolver essa discricionariedade judicial.

Parte-se da necessidade de integrar à concepção de decisão judicial, a questão da separação entre direito e moral da própria Teoria Pura do Direito e de seus fundamentos democráticos relativistas.

Para Kelsen não há uma regra moral absoluta que possa definir a interpretação justa ou correta, assim como não há respostas mais adequadas ou mesmo procedimentos absolutos de justificação moral. Compete unicamente à subjetividade da autoridade essa determinação. É nesse ponto que se torna essencial integrar a obra teórica do autor com seus textos políticos, incluindo a questão do relativismo filosófico como elemento essencial para compreender a posição de Kelsen quanto ao papel da decisão judicial no sistema normativo, visto a necessidade, portanto, de compreender essa decisão voluntária do magistrado.

Objetiva-se, de modo geral, esclarecer o problema da decisão judicial em Kelsen e as consequências do relativismo moral no que se refere ao problema da discricionariedade do intérprete autêntico. Apresentam-se, a título de objetivos específicos, propor regras de interpretação com caráter analítico que possam elucidar o papel da decisão judicial e viabilizem uma leitura científica das normas sem recorre a qualquer espécie de moralismo.

Analisar-se-á também o processo de dinâmica normativa sob a questão da decisão judicial, apresentar, a partir dessa dinâmica da base do ordenamento, a concepção relativista da moral em Kelsen e, finalmente, propor a construção de regras analíticas de interpretação dessa decisão judicial, abordando a hermenêutica da decisão judicial.

Busca-se, em síntese propor regras analíticas de Interpretação, que, portanto, não acrescentam conteúdo ao direito, apenas esclarecem a pluralidade de sentidos das normas e não elegem qualquer um deles como o sentido mais adequado, verdadeiro ou justo. 


\section{ANÁLISE DA SUBJETIVIDADE DAS DECISÕES JUDICIAIS SOB A PERSPECTIVA}

RELATIVISTA DE HANS KELSEN

A presente investigação científica utilizará o método de abordagem indutivo, permitindo-se chegar a uma conclusão específica, analisando a problemática proposta.

Parte-se, portanto, de um estudo abrangente das decisões judicias, até à analise do elemento subjetividade, com maior ênfase na perspectiva relativista de Kelsen.

Abordar-se-ão aspectos gerais das decisões judiciais, da ética e do elemento moral, além do contexto histórico, conceitos e posições doutrinárias e no que se refere ao método de procedimento, serão utilizados: o histórico-evolutivo, mostrando como as decisões judiciais vêm sendo proferidas hodiernamente, pelos Juízes operadores do Direito.

Trata-se também sobre o reflexo que as decisões judicais imprimem no ordenamento jurídico brasileiro ao longo dos anos; e o método comparativo, momento em que se apresentam divergências entre as vastas possibilidades de decisões judiciais, dos seus diversos fundamentos, aspectos e maneiras no momento em que são proferidas.

Por fim, quanto às técnicas de referências, é necessário enfatizar a opção pela pesquisa bibliográfica como principal fonte de pesquisa, ao passo que a documentação indireta é empregada no seio da pesquisa bibliográfica e documental.

Uma vez empreendida a análise proposta, segundo a metodologia empregada para tal, conclui-se que, em que pese, na contemporaneidade, não ser possível trabalharmos com um conceito absoluto de verdade, na sentença judicial, quanto maior for o seu conteúdo ético, mais próximo estará do valor justiça.

\section{FUNDAMENTOS DA DECISÃO JUDICIAL NA TEORIA PURA DO DIREITO}

Preliminarmente, se faz premente elucidar que, se tratando de decisões judiciais, as obras de Kelsen passam por significativas reformulações em face das várias edições da Teoria Pura do Direito (TPD) e da Teoria Geral das Normas (TGN), de modo que, os conceitos de Kelsen se dividem em quatro períodos: fase construtivista, transcendental, realista e analítico linguística.

É sabido que, antes mesmo da primeira edição da Teoria Pura do Direito Kelsen já havia iniciado os seus primeiros escritos contra a doutrina tradicional de subsunção da norma geral ao caso concreto e na obra intitulada de "Compendio de Teoria General del Estado" Kelsen já havia definido o significado de sentença judicial como sendo mais uma fonte criadora do Direito, representando a continuidade do processo e a produção de normas (KELSEN, 1986). 
Na primeira edição da Teoria Pura do Direito o problema da aplicação das normas limita-se a incongruência entre as normas gerais e a sua aplicação e essa oposição à doutrina tradicional limita significativamente o papel da criação normativa da autoridade.

Tem-se que essa é a fase mais forte do neokantismo, visto que, nesse momento a estrutura do sistema tem caráter lógico fundamental para a possibilidade de conhecimento do direito de modo que Kelsen não poderia aceitar a tese da discricionariedade judicial defendida na TGN, visto que a mesma contraria a unidade lógica do sistema da hierarquia normativa, imprescindível para o conhecimento puro do direito. (KELSEN, 2002).

Apenas partir da segunda edição da TPD o problema da aplicação das normas gerais torna-se mais significativo, contudo, mantendo-se relativamente atrelada ao neokantismo da primeira edição.

Ademais, Kelsen traz a tese da ordem jurídica, iniciando com a pressuposição da norma hipotética fundamental e terminando com a aplicação da norma geral ao caso concreto. Por sua vez, nesse último aspecto, o autor aborda as questões referentes ao problema da aplicação dessas normas gerais, dividida especialmente nos seguintes aspectos: o caráter constitutivo da decisão judicial, a relação entre a decisão judicial e a norma jurídica geral a e a dicotomia entre a segurança jurídica e a flexibilidade normativa.

\section{INTERPRETAÇÃO E INDETERMINAÇÃO DAS NORMAS}

Para Kelsen (2009, p. 64) as normas carecem de determinação semântica tem face da pluralidade de sentidos possíveis, situação que por si agrava a discricionariedade do julgador. Por sua vez, o real significado das normas, ao final do sistema normativo, é dado pela autoridade judicial, impondo sua interpretação como sentido objetivo de ato de vontade, motivo pelo qual a interpretação da autoridade cria direito através do seu sentido subjetivo.

A indeterminação semântica das normas reflete em todas as esferas e hierarquias judiciais, desde a norma constitucional, até a sua concretização na decisão do julgador. Ocorre que, a partir da concretização das normas o magistrado vê-se incumbido de interpretar as normas ao caso concreto possuindo o intérprete uma certa discricionariedade na decisão.

A relação entre um escalão superior e um escalão inferior da ordem jurídica, como a relação entre Constituição e lei, ou lei e sentença judicial, é uma relação de determinação ou vinculação: a norma do escalão superior regula como já se mostrou o ato através do qual é produzida a norma do escalão inferior. (KELSEN, 2009). 
Outrossim, a determinação nunca é completa de modo que a norma superior não pode vincular em todas as direções o ato através do qual é aplicada. Assim, constata-se em Kelsen uma abertura política de discricionariedade interpretativa no sistema às imprevisibilidades e às autorizações da legislação de modo que o intérprete possui um grau de liberdade na escolha do sentido de uma norma e essa liberdade é sempre um ato de vontade da autoridade que também depende do seu arbítrio, isto é, o sentido subjetivo do querer do juiz transforma-se tão somente em sentido objetivo depois de transitada a sentença.

A decisão judicial além de um ato de conhecimento, também constitui-se em um ato de vontade e, logo, um ato político, só podendo ser interpretado de maneira relativista, pois a decisão não proporciona uma legitimidade absoluta ao julgado.

Por sua vez, as interpretações contrárias à sentença não possuem o status de incorretas ou injustas, mas são politicamente indesejadas pelo magistrado, de modo que a interpretação autêntica não é tão somente uma questão de conhecimento, mas sim de vontade relativa.

Nesse aspecto é possível fazer uma crítica ao entendimento de Habermas (1997, p. 154) sobre a separação do Direito da política em Kelsen. O filósofo alemão entende que Kelsen separa o direito da política, e assevera que o positivismo de Kelsen busca a estabilidade do sistema e para tal abdica da legitimidade da decisão jurídica e das tradições éticas.

A interpretação autêntica faz parte do jurídico, referindo-se à vontade política do magistrado. Já a interpretação não autêntica é pura determinação cognoscitiva, com o único fim de determinar os vários sentidos das normas, sem, no entanto, eleger qualquer um deles.

A interpretação científica é pura determinação cognoscitiva do sentido das normas jurídicas, o que a diferencia da interpretação feita pelos órgãos jurídicos. Importante esclarecer que Teoria Pura do Direito não compactua com a ideia de que é possível obter novos direitos através de uma interpretação simplesmente cognoscitiva.

Tratando-se do intérprete autêntico tem-se que é possível sua função de criação do Direito o que permite a autocracia do magistrado, justificada na forma de justiça absoluta. Em tal contexto, faz-se necessário observar a filosofia política de Kelsen como completamente coerente com a teoria.

O fato de todos os valores serem relativos não significa de forma alguma que não existam valores e de que a autoridade não julgue conforme os seus valores, sob uma concepção política e para tal processo interpretativo é essencial também retomar a 
compreensão da distinção entre direito e ciência jurídica ocasião em que Kelsen afirma que o direito não é em si ciência, mas uma técnica de controle social (KELSEN, 1997).

Em resumo, o relativismo significa que não há valores absolutos, não existe uma justiça absoluta, e os valores constituídos através dos atos produtores de normas não podem apresenta-se com a pretensão de excluir a possibilidade de valores opostos.

Nãos bastando, Kelsen contesta o sistema de decisão de Carl Schmitt no que diz respeito às funções jurisdicionais e funções políticas, sendo que as primeiras também têm as competências das segundas.

Sobre o supracitado questionamento, Kelsen explica que:

A concepção Schmittiana acerca das funções jurisdicionais interpretativas partem do pressuposto da existência de uma contradição essencial entre essas funções e as funções políticas e a partir dessa falsa contradição, Schmitt deduz a impossibilidade de uma decisão judicial política. Igualmente, Schmitt aduz que a jurisdição constitucional não seria propriamente jurisdição, porém um ato político e, consequentemente, afastando a possibilidade da sua existência (KELSEN, 1997, p.59).

Ademais, a partir da obra Jurisdição Constitucional pode-se concluir, das objeções de Kelsen a Schmitt, a interpretação autêntica como uma função tanto jurisdicional quanto política; a ponderação de interesses de acordo com a liberdade discricionária; e a exposição da real conjuntura de interesses dentro de um processo litigioso.

Nesse sentido, conclui-se que a interpretação autêntica das normas expressa os valores do magistrado, pois representa a sua escolha do sentido da norma geral no caso concreto. Portanto, a interpretação é também um ato político e a neutralidade tão questionada em Kelsen não se aplica a esse intérprete autêntico, mas tão somente ao cientista do direito.

\section{O FORMALISMO E O REALISMO NA INTERPRETAÇÃO DAS NORMAS}

O problema da interpretação das normas jurídicas para Hans Kelsen já se encontra na primeira edição da TPD e na segunda edição o autor sistematiza-o de tal maneira a torná-lo 
questão de âmbito central para a compreensão de todo texto, com destaque para o papel criador do intérprete autêntico na determinação da norma geral ao caso concreto.

Na primeira edição há, nos pressupostos da interpretação, o rompimento com a teoria da interpretação vigente até então de modo que Kelsen discorda da exegese interpretativa e a acusa de ideologização jusnaturalista da busca de um único sentido para as normas a serem aplicadas. Já na segunda Kelsen apresenta a tese semântica da múltipla significação normativa, inovando no aspecto voluntarista da fixação da moldura de sentidos da norma.

Após traçar sua delimitação do objeto em toda a obra, o autor aprofunda a distinção das duas formas de interpretação das normas a autêntica e a inautêntica: a primeira é definida como um ato de vontade, discricionária e peremptória; a segunda, como um ato de puro conhecimento, sem outro fim que não de determinar cognitivamente todos os significados da norma.

Entende-se por realismo jurídico a corrente filosófica predominantemente norteamericana que tem por principal característica a negação do formalismo no sentido da determinação da norma geral ao caso concreto e para esta corrente o magistrado decide de acordo com o que os fatos provocam em seus ideários, e não em função de regras gerais que levariam a resultados particulares, de modo que juízes responderiam muito mais aos fatos do que às leis e vários são os fatores que marcam a atuação dos juízes.

Warat (1983, p. 50) utilizada da teoria kelseniana para uma refutar o normativismo através da sua defesa de uma epistemologia crítica da ciência que recusa o rigor analítico e o substitui pela concepção de contexto social, vista como um subsistema do sistema social global. Por sua vez, o Direito, para Kelsen, é norma, pura forma sem qualquer conteúdo, situada não se sabe onde, mas, com certeza, fora do mundo fenomenal das relações humanas.

Matos (2006, p.100) sustenta a necessidade da interpretação formalista da TPD e nesse caso verifica-se que o autor é mais consciente dos problemas acerca da evolução do conceito de interpretação em Kelsen, porém que insiste na não ruptura dos conceitos kelsenianos e na não adequação ao realismo jurídico em relação ao problema da interpretação e aplicação do Direito.

Em contrapartida, a leitura realista defende a recusa do próprio Kelsen ao formalismo de regras. Para estes, Kelsen teria superado o reducionismo lógico-semântico das suas primeiras obras e adotado um irracionalismo da interpretação. O que os autores também destacam nessa concepção é a adaptação dessas primeiras obras do autor em respostas as críticas a partir da segunda edição da TPD e, especialmente, a partir da TGN. 
Destaca-se Dimitri Dimoulis (2006, p.199) como um dos autores a interpretar a indeterminação semântica das normas e consequentemente definir o realismo jurídico como método em que resulta as alterações da obra de Kelsen.

O estudo da teoria da interpretação de Kelsen desmente a difundida opinião que o apresenta como adepto da aplicação automática das leis e como crítico da subjetividade do juiz, mas esse desafio pessimista não é específico de Kelsen, visto que caracteriza todo realismo jurídico que adota o ceticismo em relação às normas. (DIMOULIS 2006).

Nega-se a possibilidade de construção de regras interpretativas por parte de Kelsen em decorrência da sua adoção do realismo jurídico, o que inutilizaria também qualquer teoria da interpretação e mesmo a formação de regras de interpretação. O aplicador pode desrespeitar a moldura que delimita sua competência, tal como qualquer pessoa pode cometer um crime violando normas de proibição.

Kelsen equipara a aplicação correta e incorreta das normas, já que não indica como e porque pode ser censurado quem desrespeita a moldura. Isso significa que a moldura existe, mas não vincula efetivamente o aplicador. Estamos aqui diante de uma confusão entre ser e o dever ser na aplicação do direito que revela um Kelsen partidário do realismo jurídico, apesar das críticas que ele endereça a essa corrente de pensamento.

Tanto Hart como Kelsen apresentam argumentos consistentes para afastar o ceticismo conceitual, comprovando com base em suas próprias teorias que não há sentido em se falar em um conceito de Direito que abarque somente decisões judiciais e a sua predição.

Verifica-se ainda uma posição intermediária entre formalismo e realismo, a realista normativista ou realista moderada que não adere estritamente nem ao realismo no que concerne à decisão judicial, muito menos mantem o formalismo das primeiras obras. Assim, conclui-se que são insuficientes as leituras tanto realistas quanto formalistas da obra de Kelsen. Ocorre que as mudanças conceituais, especialmente da norma fundamental, constituem uma ruptura do normativismo; entretanto, não há como ler coerentemente a própria TGN se admitirmos o completo ceticismo de regras em Kelsen.

Tratando sobre a fundamentação kelseniana relativista da moral não apenas na TPD e na TGN, faz-se necessário investigar as fontes valorativas do autor para melhor compreender as suas razões de excluir a moral da aplicação das normas e as consequências de tal exclusão.

Para Kelsen, a validade da decisão judicial não depende da sua legitimação ou justificação, tanto na forma de princípios morais, ponderação ou razoabilidade, motivo pelo 


\title{
ANÁLISE DA SUBJETIVIDADE DAS DECISÕES JUDICIAIS SOB A PERSPECTIVA RELATIVISTA DE HANS KELSEN
}

qual discute-se sobre o problema do relativismo moral e como tal concepção determina a decisão judicial, especialmente quanto a discricionariedade interpretativa do magistrado.

Assim, constitui-se a regra de interpretação que considera toda decisão como despossuída de fundamento moral. Observa-se, então, que a partir desse fundamento de validade fica evidente a tendência relativista e anti-ideológica da TPD que tratando sobre decisão judicial não representa uma variável ao direito.

Verifica-se que na validade da decisão judicial não é afirmado qualquer valor transcendente ao direito posto e a exclusão da moral nas decisões judiciais se constitui em uma técnica de controle social centralizada, ao passo que a moral representa uma técnica de controle social descentralizada. Assim, mesmo a autoridade arrogando-se competente para aplicação de princípios morais na sua sentença, interpreta-se tal apenas como o sentido ilusório e absolutista dessa autoridade na interpretação da norma jurídica.

No texto “A Democracia”, Kelsen desenvolve a dicotomia entre absolutismo e relativismo filosófico e aduz que:

\begin{abstract}
Torna-se essencial ser analisado para compreender a incapacidade epistêmica da moral delimitar o sentido de uma norma e conforme ensinamentos de Kelsen desde que Aristóteles apresentou a teoria política e a ética correlacionadas, tornou-se pacífico a estreita ligação entre elas (KELSEN, 200, p. 34).
\end{abstract}

Nesse âmbito, Kelsen aduz que o relativismo filosófico defende a doutrina empírica de que a realidade só existe na esfera do conhecimento humano, e que a realidade, enquanto objeto do conhecimento, é sempre relativa ao sujeito cognoscitivo.

A partir do absolutismo filosófico encontra-se a concepção na qual a norma posta é válida quando corresponde ao direito natural constitutivo de um valor de justiça incondicional, que se opera em um juízo de apreciação do direito positivo como justo ou injusto, vinculando, então, sua validade à sua legitimidade e a partir do relativismo filosófico Kelsen afirma que a validade das normas de direito positivo não depende da relação em que se encontra com a norma de justiça. 
Tratando sobre a análise da impossibilidade epistêmica do absolutismo filosófico, Kelsen contrapõe-se à doutrina do jusnaturalismo, a qual considera a formadora dessa ilusão absolutista da moral, conclui a irrelevância de tais argumentos para a validade de uma ordem jurídica, afirmando o aspecto exclusivamente teológico da doutrina naturalista.

A natureza funciona como autoridade normativa, como legisladora dos valores humanos. Quem está de acordo com suas supostas normas absolutas atua justamente. Tais normas são consideradas imanentes e natural da conduta humana, a qual é descoberta através de uma atenta análise do comportamento, sendo, portanto, cognoscíveis.

Não são normas do direito positivo, variáveis no tempo e no espaço, mas normas dadas anteriormente ao surgimento do Estado e do direito, como características sobrehumanas de invariabilidade e imutabilidade. (KELSEN, 2003).

Disto se conclui que as ideias do jusnaturalismo são sempre passíveis da crítica da falácia naturalística, pois tal postula uma concepção de bem supostamente advinda da natureza do comportamento humano e que, de fato, não passa das conjecturas naturalizadas pelo moralista. Ademais, para o jus moralista, a natureza pode ser interpretada como um todo organizado com uma finalidade quando se admite e que são postos certos fins ao acontecer natural por aparte de uma vontade transcendente e como tal, esta validade é tida como absoluta e imutável.

\section{ABORDAGEM HERMENÊUTICA DA DECISÃO JUDICIAL E AS REGRAS DE INTERPRETAÇÕES}

Tratando-se sobre a origem do relativismo filosófico, constata-se que toda legislação é compreendida como um sentido de um ato de vontade, de modo que o conceito de direito passa pela determinação da vontade, bem como a decisão que também é compreendida a partir desse ato de vontade, sendo que essa não pode ser determinada por uma razão prática.

Streck (2008, p. 105) sustenta que o positivismo jurídico defendido principalmente por Kelsen envolve ou pressupõe o subjetivismo ético, portanto um relativismo ético. Essa tese também configura a contraposição entre o positivismo jurídico e o jusnaturalismo.

Por sua vez, Kelsen se contrapõe à possibilidade do objetivismo moral, isto é, à possibilidade das normas morais serem conhecidas independentemente dos sujeitos que a postulam. Para Kelsen, quando se admite a moral como sentido subjetivo do ato de vontade, a mesma não pode ser conhecida além desse mesmo sujeito que a defende. 
A proposta de um objetivismo moral para Kelsen não tem como fundamento regras lógicas ou racionais, mas, sobretudo é uma manifestação emocional do sujeito que a postula e na hipótese do magistrado justificar sua decisão como absolutamente justa essa mesma decisão racionalmente não pode ser interpretada como uma manifestação objetiva da moral, mas tão somente como uma ilusão emocional desse magistrado.

Conclui-se que a pretensão de justificação de valores morais absolutos, os quais teriam competência de vincular a validade da decisão judicial a uma concepção de bem, são, para Kelsen, resultado não da universalização ou racionalização desses mesmos valores, mas consequência do estado emocional da autoridade que os invoca com o intuído de legitimar suas decisões. Isso posto, verifica-se que a decisão judicial constitui-se no sentido do ato de vontade e sua justificação compreendida psicologicamente e não moralmente.

A tese da hermenêutica filosófica ou da resposta adequada à Constituição, de Lenio Streck estabelece a abertura hermenêutica para preservar a autonomia do direito e realizar o controle da discricionariedade judicial, assim, garante a integridade e coerência do direito contra teorias pragmatistas, estabelece a fundamentação de legitimidade e garante o controle das decisões judiciais e, por fim, viabiliza uma forma de o cidadão aferir se a resposta do judiciário foi, de fato, constitucionalmente adequada.

Nesse ínterim, as regras de interpretação assemelham-se mais a instrumentos de entendimento das normas do que a espelhos da realidade observada. Sendo assim, admite-se que a possibilidade de uma proposta da abordagem hermenêutica em Kelsen fixa-se no âmbito da filosofia pragmática no que concerne à interpretação, especialmente após a reformulação da norma fundamental, não mais hipotética, mas ficcional.

Ademais, a abordagem hermenêutica da obra de Kelsen defende a não representação privilegiada da realidade e nem a tradução dessa realidade para o jargão comum dos juristas, mas uma forma de edificação semântica dos sentidos possíveis das normas, sendo que mesmo os sentidos contraditórios e pertencentes a culturas diferentes são considerados válidos como hipótese de sentido possível de uma norma, pois nem mesmo o cientista do direito poderia interpretar os diversos sentidos das normas.

Kelsen não nega a origem factual do direito, o que acontece é que o dever-ser de uma norma distingue-se do próprio fato criador das normas, mas não em sua origem, que continua sendo uma realidade factual, traduzido em sentido objetivo de um ato de vontade e a decisão judicial também encontra-se originalmente como uma realidade factual e é interpretada apenas em um segundo momento como um sentido de um ato de vontade. 
A interpretação das decisões são vistas, nesse primeiro momento como uma manifestação observável no espaço e no tempo. Então, consequentemente, exclui-se a hipótese da origem racional da decisão judicial. Como ato de vontade, então, interpreta-se, pelo menos nesse primeiro momento, a subjetividade do intérprete autêntico na aplicação da norma no sentido de que ele decide conforme a sua vontade. Tal subjetividade transforma-se em objetividade apenas quando transitada em julgada a sentença.

Quanto ao sentido objetivo de um ato de vontade, tem-se que no primeiro momento admite-se, como característica específica da decisão judicial, o acontecer fático da mesma em sua origem e a recusa da razão como seu fundamento.

Ocorre, entretanto, que a sentença, apesar da sua origem factual, não é determinada em seu conceito final por esse mesmo ato de vontade. A decisão judicial, assim como todas as normas, representa o sentido desse ato de vontade. De fato existe um ato que constitui a norma, porém ela mesma não se resume a esse, mas é entendida como o seu sentido de vontade.

Tratando sobre o reconhecimento da objetividade das normas, Kelsen afirma que a característica da objetividade do sentido do ato de vontade se caracteriza quando esse mesmo sentido de ato de vontade é considerado como obrigatório não apenas do ponto de vista do indivíduo que põe o ato, mas também do ponto de vista de um terceiro desinteressado, mesmo depois da vontade do indivíduo que institui esse dever-ser ter cessado.

Em resumo, então, toda norma é o sentido objetivo de um ato de vontade. Sendo a decisão judicial também uma forma de constituição normativa, também ela se determina como sentido objetivo do ato de vontade.

Sobre a validade da decisão judicial, que independe da sua legitimação ou justificação, entende-se que, mesmo que a decisão judicial, por mais que se arrogue justa e correta, sua validade independe dessa justiça autorreferente.

Da mesma forma, não há nenhuma norma de justiça que vá determinar a validade da decisão por não corresponder aos seus critérios absolutistas. Como regra de interpretação, o cientista do direito ignora a legitimidade ou a justificação da decisão judicial como vinculante da sua validade. Portanto, uma decisão, mesmo considerada injusta, não razoável ou imponderável ainda assim mantêm-se como norma jurídica.

Ademais, é fato que a decisão judicial segue um escalonamento que culmina na pressuposição da norma ficcional fundamental, vez que, a normatividade segue um escalão normativo desde a norma fundamental até a concretização das normas gerais nos casos 
concretos. Assim, a decisão judicial segue um escalonamento que tem na norma fundamental a unificação do conjunto normativo.

Por fim, partindo do pressuposto que toda decisão judicial imputa uma coerção socialmente organizada, para Kelsen, a pena está vinculada ao problema da evolução antropológica da sociedade no que diz respeito a separação entre o que se entende por natureza e o que se entende por sociedade, isto é, está novamente vinculada a ideia de separação entre ser e dever-ser.

A pena não se trata de uma retribuição racional ao delito cometido pelo sujeito contra a sociedade tese clássica e adotada por Kant (2005, p; 24), ou seja, a retribuição penal fundase no princípio da causalidade ou das associações necessárias, enquanto a imputação penal, tese defendida por Kelsen, baseia-se na ideia de irracionalidade das penas.

Enfim, para Kelsen o direito penal não passa da aplicação das paixões de forma legitimada não racionalmente, mas pelos hábitos e consuetudinariamente, o que se justifica sua renúncia ao princípio da retribuição, como queria Kant na doutrina do direito, para simplesmente sustentar imputação de uma pena a determinado ato.

A desconsideração do princípio da retribuição e adoção da imputação também aparece como fundamento da decisão na própria TPD e estando a decisão judicial em conformidade com as leis consideradas naturais por essa doutrina metafísico religiosa, essa mesma decisão tem competência de aplicar uma pena sob a justificação de que ela é a retribuição causal do crime.

Acreditando que a decisão judicial leva em consideração o direito internacional como variável do escalonamento normativo, Kelsen articula o problema do direito internacional e como tal refletirá na validade da ordem jurídica.

Para Kelsen a questão da soberania é superada pelo estado moderno na consideração da unidade do direito internacional e do direito nacional. Mesmo os sistemas fechados e nacionalistas são explicados não pela dualidade entre direito nacional e internacional, mas pelo monismo entre a lei constitucional e internacional, superando-se o problema da soberania.

Nesse sentido, toda a evolução jurídica faz com que se desapareça a linha divisória entre direito internacional e ordem jurídica do Estado singular, dirigida a uma centralização cada vez maior de uma comunidade universal de direito. Portanto, as normas do direito internacional devem ser consideradas simultaneamente válidas às normas do direito nacional ou serem desconsideradas por esse mesmo Estado. 
Isto posto, verifica-se que não há qualquer conflito entre direito internacional e direito nacional através da concepção monista de Kelsen. Entretanto, o problema se concentra quando a norma internacional contraria uma norma constitucional. Nesse sentido, questionase a quem deve o magistrado recorrer para qualificar sua sentença como objetivamente válida através da pressuposição de uma norma fundamental.

Kelsen entende que, mesmo existindo um primado do direito nacional, ainda o monismo entre direito internacional e direito nacional é inevitável e uma política nacionalista só pode reconhecer o direito internacional como juridicamente válido se ele se encontra pareado com a sua própria constituição.

Nesse sentido, pode-se concluir o inevitável alargamento da juridicidade em relação ao problema da decisão judicial em Kelsen e por sua vez, a decisão do juiz, a partir das considerações monistas do autor, acaba por ser mais abrangente, englobando normas não apenas do direito positivo nacional, mas também normas do direito positivo internacional, o qual, por fim, será quem funcionará como sistema normativo fornecedor do sentido objetivo dos atos de vontade globalmente considerados.

Observa-se, enfim, que a indeterminação do sentido das normas não pode ser considerada superada pela proposição moralista da qual vê no direito internacional regras práticas de ação que determinam o sentido justo ou correto da interpretação a partir da comunidade internacional.

\section{CONCLUSÃO}

Verificou-se que Kelsen problematiza a questão da discricionariedade judicial desde suas primeiras obras. Entretanto, há de se aceitar que na sua fase inicial, de formação do seu pensamento, Kelsen postula uma forma lógica de delimitação dos sentidos das normas, a qual poderia limitar a discricionariedade judicial na aplicação das normas gerais nos casos concretos através de um quadro previsível de possíveis sentidos da norma.

Admitindo-se então a possibilidade de periodização das teses de Kelsen, consequentemente há de se refutar a leitura formalista normativista do sentido das normas. Ocorre que, de fato, encontramos referência textual nas primeiras obras sobre a possibilidade de determinação semânticas das normas através do método lógico e formal.

Contudo, a leitura formalista não se sustenta desde a década de 1940, quando Kelsen lança a TGDE com elementos pós neokantianos no que concerne à interpretação judicial. 


\section{ANÁLISE DA SUBJETIVIDADE DAS DECISÕES JUDICIAIS SOB A PERSPECTIVA RELATIVISTA DE HANS KELSEN}

Assim, o autor se autocorrige e, consequentemente, invalida as suas concepções de interpretação normativa através de uma lógica formal.

Constata-se que, ao contrário da leitura formalista, surge na literatura especializada o entendimento majoritário de que Kelsen teria, então, abandonado completamente o neokantismo e o formalismo jurídico e adotado o realismo jurídico para explicar a completa discricionariedade na aplicação da norma pelo intérprete autêntico.

Nesse caso, defende-se uma ruptura radical entre as primeiras obras e a fase madura da teoria da decisão de Kelsen. Argumentam os defensores dessa tese, que, especialmente em função da não limitação da moldura de significados a partir da segunda edição da TPD, da mudança da norma fundamental, de hipotética para ficcional e a distinção entre normas jurídica e normas lógicas na TGN, o autor teria invariavelmente e contrariamente a suas primeiras obras, adotado um ceticismo de regras, o qual lhe aproximaria do pragmatismo norte-americano e resultaria da revogação de toda sua produção teórica anterior à segunda edição da TPD.

Entretanto, apesar de se admitir como coerente a leitura realista a partir últimas obras, a concepção mais adequada defende a possibilidade de um realismo normativista ou, em outros termos, um realismo moderado em Kelsen. Quanto ao relativismo moral, observase que é no aspecto da decisão judicial que melhor observa-se a influência da teoria cética da moralidade inserida na teoria pura do direito.

Outrossim, verifica-se que a decisão judicial, mesmo arrogando-se justa ou correta, é interpretada sempre como relativa, visto a insustentabilidade de normas morais absolutas, válidas para todos em qualquer tempo e espaço.

Vislumbra-se a coerência entre as teses políticas de Kelsen e a sua teoria jurídica. Nesse ponto também se observa o maior contraste com as teorias moralistas hodiernas. Comparando-se o positivismo exclusivo de Kelsen com as teses de conexão entre direito e moral observamos a completa disparidade entre as teorias da justiça e o positivismo jurídico do mestre de Viena. Embora, há de se admitir, que a tese de Kelsen contra as teorias de conexão está fundada na sua refutação do jusnaturalismo.

Isso posto, tem-se que, mesmo admitindo-se essa falha no pensamento de Kelsen, defende-se, sob o postulado da possibilidade, ainda que ficcional, do conhecimento objetivo do sentido das normas, a possibilidade, através de regras de interpretação deduzidas do texto do autor, compreender o sistema normativo como um todo e analisá-lo no intuito de descrever os sentidos das normas com a esperança futura do legislador delimitar essas normas e, 
consequentemente, restringir a discricionariedade do magistrado, sem, contudo, recorrer a qualquer espécie de moralismo.

Já no aspecto essencialmente metafísico do direito, em que pese entendimentos divergentes, pode-se inferir uma patente hierarquia, de modo que o Direito Natural estaria em primeiro lugar, e após a Ética, a Moral e por fim, o Direito positivo.

O Direito Natural corresponde a um sentir no mundo das ideias, sendo o primeiro a surgir. A Ética, por sua vez, se relaciona com os princípios fundamentais para a formação do mundo cultural, correspondendo a um verdadeiro patrimônio espiritual da consciência civilizatória da humanidade.

Já a Moral encontra-se interligada aos costumes e diz respeito à norma elaborada, no seu estágio de positivação legal, sendo, pois, um patrimônio cultural de cada grupo social.

Por fim, quanto ao Direito Positivo, apresenta-se como um conjunto de regras feitas pelo homem e para o homem.

Entende-se ainda que o Juiz de Direito é operador que interpreta o Direito, e ,para anunciá-lo, ele se expressa na linguagem de poder do Estado. Esta é a tônica do Direito Positivo, ou seja, o Direito Posto, resultado de uma convenção social, previsão constitucional, característica dos países, no mínimo, razoavelmente democráticos.

Por fim, contata-se que, embora Kelsen assevere que Ética e Justiça são temas extrajurídicos, em virtude de seu inegável conteúdo metafísico, tem-se, porém, que a justiça objetivada em uma decisão judicial, torna-se razoavelmente possível na intuição que o Julgador possa ter do direito.

\section{BIBLIOGRAFIA}

DIMOULIS, Dimitri. Positivismo jurídico: introdução a uma teoria do direito e defesa do pragmatismo jurídico-político. São Paulo: Método, 2006.

HABERMAS, Jürger. Direito e democracia: entre facticidade e validade. Volume I. Tradução: Flávio Beno Siebeneichler. Rio de Janeiro: Tempo Brasileiro, 1997.

KANT. Immanuel. Crítica da razão pura. Tradução: Valerio Rohden e Udo Baldur Moosburger. São Paulo: Editora Nova Cultural Ltda, 2005.

KELSEN. A justiça e o direito natural. Tradução: João Baptista Machado. Coimbra: Almedina, 2009.

Direito internacional e Estado soberano. Tradução: Marcela Varejão. São Paulo: Martins Fontes, 2002.

. Teoria geral das normas. Tradução: José Florentino Duarte. Porto Alegre, Fabris, 1986. 
Teoria pura do direito. Tradução: João Baptista Machado. 8. ed. São Paulo: Editora WMF Martins Fontes, 2009.

MATOS. Filosofia do Direito e Justiça na obra de Hans Kelsen. 2. ed. Belo Horizonte: Del Rey, 2006.

STRECK, Lenio Luiz. Jurisdição constitucional e decisão jurídica. 3.ed. São Paulo: Editora Revista dos Tribunais, 2008.

WARAT, Luis Alberto. A pureza do poder: uma análise crítica da teoria jurídica. Florianópolis: Editora da UFSC, 1983. 